\title{
Towards a Knowledge-Based Theory of Developing Sustainable Visions: The Theory Wave
}

\author{
Alexander Kaiser \\ WU - Vienna University of Economics and Business \\ alexander.kaiser@wu.ac.at
}

\begin{abstract}
Although research and practice agree that visions are essential for organizations, the process of vision development remains elusive in academic literature. Presenting the "theory wave", this paper proposes a knowledge-based theory for developing sustainable visions to guide the creation of measures and actions in the future. Central to the theory wave, we suggest three features that characterize the development of sustainable visions; (1) learning from an envisioned future, (2) need orientation and (3) a wavelike process combining top-down and bottom-up approaches. Furthermore, by enhancing the creation of different kinds of knowledge, the theory-wave entails aspects of research on knowledge creation and thereby, it provides a new perspective on the field of vision development.
\end{abstract}

\section{Introduction}

Visions help us reaching our goals. Similar to a dream, they depict our desired future and motivate us intrinsically. Also for a company it is essential to have a vision as a driving force for all employees in order to be innovative and successful. Nonaka points out the importance of firms' visions for their differentiation from other firms when he states that "what differentiates firms from one another is their vision of the future and their practical ability to act to realize that future by using their aesthetic sensibilities to create knowledge" [1, pp. XI, 2].

A vision impacts organizational performance, group effectiveness and growth in entrepreneurial firms. It can create the spark that lifts organizations beyond the mundane and can build both staff and customer satisfaction [2, p. 103f.]. There seems to be consensus (e.g. [3], [4]) that a vision has to capture the following elements: First of all, a vision deals with a state in our future, most likely our mid-term to long-term future. Furthermore, this vision usually does not contain any strategies or concrete ways of how to realize it. And not at least, a vision can be seen as a (future) ideal situation. The development of a vision is not only essential for our personal lives but also for an organization's successful existence. The more vivid and inspiring a vision is, the more benefits it has to all concerned. Moreover a vision development process can be described as a knowledge creating process as well [5]. A sound method of developing visions in companies is an appropriate and important instrument within the whole knowledge management of a company, since not only the aspect of knowledge creation is covered but also knowledge sharing transfer and exchange. Although the importance of a vision is unquestionable and widely accepted in practice, especially the process of vision development is elusive in academic literature. Yet, little to no theoretical work has been done to come up with a theory for developing visions on the individual level as well as in social systems.

The purpose of this paper is to propose a knowledge-based theory for developing sustainable visions as a fundament from which concrete methods can be derived in the future. The remainder of this paper is organized as follows. First we provide the theoretical background for our research and give an overview about related work as well as an overview about the two case studies we have used for our study. Subsequently we introduce the theory wave as a knowledge-based theory for developing sustainable visions and describe in detail the components of this theory as well as the connection between these components. Finally, we discuss our findings and present limitations of our work as well as implications for further research.

\section{Theoretical background, related work, research gap, research question \\ 2.1. Definition of vision}

It should be noted that a vision is different from a goal and an objective. A vision is the documented purpose that is detailed, customized, unique, and reasonable. A goal is a general statement of intent that remains until it is achieved or no longer needed as the direction changes. An objective, on the other hand, is a specific and product-oriented statement of intended accomplishment that is attainable, observable, and measurable by specifying no more than what, where, when and how. In contrast to an objective, a vision focuses on the "why". Therefore, a vision does not change but becomes refined, whereas plans or strategies to achieve it (e.g., goals) remain flexible and changeable [6, p. 250]. Various 
definitions exist for the term vision. O'Connell summarized a lot of these definitions: "It is an idealized goal state, a set of blueprints for the future, an agenda, a map for members to follow, and an image of what needs to be achieved. It may include both long-term, future-oriented goals and emotional appeals embedded in a set of values; it is focused on change and depicts a future that is credible, realistic, attractive, inspiring, and better than the status quo" [2, p. 105]. Collins and Porras stress that it is very important to develop a vivid description of this envisioned future as there is needed "such a big commitment that when people see what the goal will take, there's an almost audible gulp" [7, p. 75].

Based on various definitions of vision in the literature, our definition is the following:

A vision is a clear image of a fulfilling and desirable future which can be described to others and which is possible to be realized in any - maybe extremely challenging - way, shape or form.

\subsection{Vision development}

Synthesis of the literature suggests that the vision development occurs in four ways [2, p. 109f]: (1) A leader creates the vision individually and communicates it directly to followers; (2) A key leader and group of top managers create and communicate the vision to followers; (3) Co-creation of a vision by a leader and followers in a sensemaking and sense-giving process, with the leader proposing a vision that iteratively is modified through exchanges between the leader and followers. (4) Development of a vision when the organization as a whole engages in a large group collaborative process.

As already mentioned only little theoretical work has been done in the field of vision development as such. Maybe one of the best known approaches is the work by Peter Senge, who states that the skills involved in building shared vision include the following [6,p.13f]: encouraging personal vision, communicating and asking for support, visioning as an ongoing process, blending extrinsic and intrinsic visions and distinguishing positive from negative visions. He also stresses the importance of the tension between the presence and the future as a resource, when stating that "Creative tension comes from seeing clearly where we want to be, our "vision," and telling the truth about where we are, our "current reality." The gap between the two generates a natural tension" [8, p. 9]. But Senge's work does not say much about the vision developing process and the theoretical foundations such a process is based on.

Another model which has a strong connection to vision development is the Intentional Change Theory
(ICT) by Richard Boyatzis. His model proposes that a change process involves a sequence of discontinuities, called discoveries, which function as an iterative cycle in producing the sustainable change at the individual level. One of these are the ideal self and a personal vision as well as the real self and its comparison to the ideal self. This results in an assessment of one's strengths and weaknesses, in a sense a personal balance sheet [9, p. 613]. The ideal self plays an important role in the ICT. It is the driver for a personal vision and there are three major components converging into the articulation of the person's ideal self, and the resulting personal vision: (1) The ideal self contains imagery of a desired future; (2) the ideal self is emotionally fueled by hope; (3) the third component of the ideal self is the person's core identity [10, p. 626f].

Nonaka stresses the great importance of a vision for the knowledge creating process as well in his original SECI model [11] as also in his enhanced theory of the knowledge creating firm ([12], [13]). However Nonaka himself does not give too much information and ideas of how to develop a vision as a driver for his theory of his knowledge creating firm.

\subsection{Sustainability}

In this paper we focus on sustainable visions. But what is the difference between sustainable visions and other visions?

Sustainability remains an elusive concept, and its nature - what it means, why it matters, who should care, and how it is achieved - is only gradually becoming apparent. The definitional expansion has resulted in a diffusion of focus and a vagueness of the direction of sustainability [6]. One of the first and still one of the most important definitions of sustainability was published 1987 in the report of the UN World Commission on Environment and Development, also known as the 'Brundtland report': "Sustainable development is development that meets the needs of the present without compromising the ability of future generations to meet their own needs. It contains two key concepts: the concept of 'needs', in particular the essential needs of the world's poor, to which overriding priority should be given; and the idea of limitations imposed by the state of technology and social organization on the environment's ability to meet present and future needs" [14]. So sustainability is defined through its capacity to meet human needs.

When we talk about sustainable visions there are at least two important aspects to cover: (1) we have to focus on visions which are purpose driven by meeting human needs and therefore long term action 
guiding; (2) the visions have to take into account the interdependence and connection to several other social systems by not compromising the ability of others to meet their needs and desires.

\subsection{Research gap and research question}

As Kim and Oki state, despite the plethora of innovative research frameworks and remarkable accomplishments, the engineering of a lucid vision is still a missing framework in the science of sustainability. A sustainable future will require a purpose-driven transformation of society at all scales, guided by the best foresight, with insight based on hindsight that science can provide (i.e., visioneering) [6, p. 250]. Van der Helm [15] criticizes that visions are still seen as a phenomenon rather than a theory and points out that the importance of vision in our relation with the future, has not deserved sufficient theoretical attention yet. "Visions have to go beyond the dreams we all foster for ourselves, our community, or for humanity as a whole, since there is an important difference between a dream and a vision.' [15, p. 103].

As shown above, there is a main research gap in the field of vision development. A theory of the development of visions that are long term action guiding regardless of the size of the system the vision aims at, is lacking. Furthermore there is also a lack of systematic procedures for vision development in the entrepreneurial environment [16]. Based on this research gap the following research question can be defined: "Which main components does a knowledge-based theory for developing sustainable visions have and how are these components connected with each other?"

\subsection{Research method}

To answer the research question, we used a case study research method to build our theory about developing sustainable visions. The overall design and conduct of this case study was guided by the approach of [17] building theory from case study data. Furthermore, we have opted for a multiple-case study because they typically provide a stronger base for theory building [18]. Two case studies, chosen from a larger set of cases, were selected for this particular study. These two case studies were chosen for reasons of theoretical sampling. It simply means that cases are selected because they are particularly suitable for illuminating and extending relationships and logic among constructs [19].

We selected the case of a vision development process in a large department of the OMV, a large multinational oil and gas company. This case has been evaluated and analyzed as part of a master thesis
[20] using structured paper and pencil interviews. As a second case we selected a vision development process in a small sized research oriented company (SERI) working in the field of sustainability. This case has been evaluated as part of another master thesis [21] using semi-structured interviews.

\subsection{The two cases}

OMV: OMV is an integrated international oil and gas company, headquartered in Vienna. It is active in the upstream (exploration and production) and downstream businesses (refining and marketing gas and power). With a workforce of around 25,500 employees in 2014, OMV Aktiengesellschaft is one of Austria's largest industrial companies. OMV owns around 4,100 petrol stations in eleven countries. OMV operates a gas pipeline network in Austria and gas storage facilities in Austria and Germany.

Our case study was conducted with the OMV group Corporate Internal Audit department, which consists of three national audit departments (Austria, Romania and Turkey) with about 40 internal auditors from these three countries. The overarching goal of this project was to develop a shared vision for the whole internal audit department, which is compatible with the main orientation of the whole OMV group. The chief audit executive of OMV supported this project and also joined the vision development process. There was a clear project schedule and the vision development process lasted for about five months covering three workshops with all members of the department. The definition of a shared vision for the department had been realized within a group collaborative process. At the end, members of the department formulated the following short overall vision together [20]:

"Keep Momentum! Internal Audit is the critical reflection of OMV's business activities. Today. And tomorrow. We are your constructive and credible dialogue partner for the value-driven development of the OMV, between the poles of risks and chances."

Based on this short vision a detailed vision has been formulated [20]. In the following we point out some parts of this vision, the full text can be found at [20] and at http://bit.ly/1Uu6eBr

"Integrity and keeping always the highest ethical standards are our underlying core values when performing our work. We act as an independent and objective function, provide fair and competent insight and take full accountability for our reports. Our critical reflection of OMVs business activities is based on the Latin proverb 'audiatur et altera pars' ('hear the other side'). Active and empathic listening combined with a healthy dose of inquisitiveness is 
our proactive approach to ask good questions with the target to find room for improvement. We seek first to understand, then to be understood in order to give honest and accurate feedback. In order to fully understand, we take the time, pay the required attention and consider the context of the work presented and the outcomes that the person or group is working toward. [...] We act as one team across the three hubs making full use of our collective intellect. Our auditors are intrinsic motivated by having meaningful goals, sufficient autonomy and resources to develop their own mastery. [...] Internal audit is regarded as a talent pool for career-minded auditors to develop skilled and driven individuals into future leaders. In that sense, we are proud to be the eyes and ears of the Board".

SERI: The Sustainable Europe Research Institute (SERI) is a Pan-European think tank exploring sustainable development options for European societies. It was set up in 1999. SERI Nachhaltigkeitsforschungs- und Kommunikations $\mathrm{GmbH}$ in Vienna - the institute with the highest turn-over and the most employees in the network so far - is among Austria's leading institutes in supporting sustainable development. Their projects facilitate the resolution of problems at the intersection of economy, society and the environment in ways that reflect ecological, economic and social responsibility. SERI provides decision makers in the areas of sustainable development with information relevant to their goals within the framework of regional, national and European sustainable policies.

Our case study was conducted with the whole staff of the SERI company which consisted of about 20 employees. The project had top-management support and the managing director was actively joining the vision development process. The vision development process consisted of two phases. In the first phase, which lasted for about 4 months, 11 members created a shared vision within a group collaborative process. This process consisted of two workshops and several coaching sessions. In a second phase additional 9 members of SERI developed a shared vision and this vision was combined with the first vision to an overall shared vision. The shared vision of the first phase has been included as separate vision into the second phase and has been so incorporated into the overall vision at the end of the process, which was the following: "SERI is a leading and internationally recognized research institute working in the field of sustainability. A team of specialized and highly qualified employees and corporate partners develops ideas and solutions for a good life on our planet today and in the future, which are scientific recommended and applicable for practice. Based on the vision development process SERI makes a regular self-evaluation which considers the most important values for SERI as well as current developments in science and practice. The annual sale is about 1 Million Euros and covers $50 \%$ research projects and $50 \%$ commercial projects. SERI has a huge base funding which enables SERI to compensate deficits from scientific projects. We are living the principle of "practice what you preach". SERI is the most important consulting company in the field of sustainability in Austria as well as in Europe. We have contributed with our work that within 10 years from now on all citizens know what it means to live in a sustainable way and to economize in a sustainable way. SERI is the most important focal point for those young researchers and scientists, who want to develop innovative solutions for a way into a sustainable world and a sustainable Austria with diverse methods and different views.

\section{The theory wave}

The Theory wave describes a knowledge-based process of developing and articulating sustainable visions. The characteristics of this theory have been derived from the two case studies described above. Even though the two case studies have very different scopes related to the organizations itself, the fields the organizations are working in as well as the size and the structure of the groups, the main aspects of the theory can be found in both case studies. This might be an indication that this theory is applicable for different levels of human organizations.

The theory wave proposes that three features characterize the development of sustainable visions:

- learning from an envisioned future

- need orientation

- a knowledge-based wavelike process comprising three steps and three discoveries that supports the development of a sustainable vision

The main aspects of each of those three features are described and discussed in the following sections.

\subsection{Learning from an envisioned future}

This approach uses our ability of imagination, theoretically established on theories of memory and prospection from the field of cognitive science (for an overview see [22]) and is inspired by Scharmer's theory of learning from the future as it emerges [23], [24]. Learning from an envisioned future consists of two parts - learning and envisioning the future.

First some thoughts about learning: Experiential learning theory defines learning as "the process whereby knowledge is created through the trans- 
formation of experience. Knowledge results from the combination of grasping and transforming experience [25, p. 41]. Hence learning is an action-reflection process based on reflecting experiences in the past.

In his theory, Kolb [25] emphasizes the central role that experience plays in the learning process, one role is subjective and personal, referring to the person's internal state and the other role is objective and environmental. These two forms of experience interpenetrate and interrelate in very complex ways.

Kolb provides a citation from Dewey's work: “An experience is always what it is because of a transaction taking place between an individual and what, at the time, constitutes his environment, whether the latter consists of persons with whom he is talking about some topic or event, the subject talked about being also part of the situation; the book he is reading [...]. The environment, in other words, is whatever conditions interact with personal needs, desires, purposes, and capacities to create the experience which is had. Even when a person builds a castle in the air he is interacting with the objects which he constructs in fancy" [25, p. 35].

Secondly, we have to consider the term "envisioned future". An envisioned future can be defined and described as the picture of an ideal, fantastic, attractive and desired future [26]. Therefore, it is very strongly connected with the idea of fulfillment life.

Using the two meanings of experiences (subjective and objective), in the case of learning from an envisioned future, those experiences are subjective - experiences in the envisioned future. Again, we recognize the action-reflection process in which knowledge is created through the transformation of imagined experiences made in the future. The most important aspects and characteristics of the envisioned future can be compared with the presence and as a consequence, knowledge is created by reflecting on "the difference which makes a difference" [27, p. 459]. More precisely, learning from an envisioned future can be defined as a reflection about features, objects and entities which have ended in the future and such which have newly come up and emerged. The idea is to be somewhat detached from today's circumstances (and its restrictions, boundaries and impossibilities) while, at the same time, being enabled to shift the thinking to come up with visionary and creative results transcending the boundaries of the current situation and environment [28]. Learning from an envisioned future uses the power and flexibility of imagination that we humans have by mentally "pre-experiencing" hypothetical future scenarios and personal events [29, p. 143]. The narrative result enables externalization of tacit dreams, wishes and desires as if they had become true and thereby generating a picture of the desired personal future from which explicit knowledge can be derived in order to act accordingly in the present.

\section{Learning from an envisioned future in the two case studies}

The evaluation of the two case studies showed that the parts within the vision development processes in which the participants were invited to learn from an envisioned future have been extremely important for the generation of new ideas and essential parts of the shared vision. However, the evaluation of interviews with participants also showed that learning from an envisioned future is not that simple and easy for everybody. Especially in the OMV case study, the cultural differences of the participants did have a significant impact on the acceptance of learning from an envisioned future at the beginning of the process. Therefore it is crucial to prepare an appropriate " $b a$ " [1, p. 35] or "enabling space" for this learning mode.

\subsection{Need orientation}

As shown above, the definition of sustainability is strongly connected with the capacity to meet human needs. One of the differences between a sustainable vision and a non-sustainable vision is that the sustainable vision is based on substantial needs. We define substantial needs as needs which are strongly connected with a fulfilling life. Therefore substantial needs are very subjective, whereas fundamental or basic needs (such as oxygen, food, water) are the same for each human being. In the following, we provide some theoretical foundations about needs for a better understanding.

Like medical conditions, needs generate feelings and desires and are expressed or manifested by signs and symptoms; those might either point to a lack of resources, like in the case of an illness, or positively seen, to the prosperity of the human being [30]. McLeod argues that knowledge of needs is inferential, meaning that needs can be derived from their manifestation. For example, having the patient reporting about symptoms, the doctor may discover by her expertise - the medical needs the patient has. Symptoms as well as signs of needs and desires can be reported and observed, respectively [30].

Following Max-Neef we can distinguish between needs and their specific satisfiers. A satisfier is seen as a concrete solution to a need; it is a form of being, having, doing and interaction, related to structures [31]. Unlike fundamental needs, satisfiers are culturally determined and might be different in 
various cultural contexts and historical periods. Needs are most fundamental and are the basis for desires and satisfiers. They are the motivational source of our acting. McLeod suggests that "needs are not themselves experienced". He argues that "needs may be indirectly manifested in desires, in feelings and in other psychological states"[30]. "What I need depends not on thought or the working of my mind (or not only on these), as wanting or desiring do, but depends on the way things really are" [32].

Of course there are several categories of needs [30], [33]. For the purpose of this paper, we focus on substantial needs as requirements to be met for the individual's fulfillment and well-being and the organization's sustainable existence. Those needs are strongly connected with a purpose and calling.

To sum up, a sustainable vision contains satisfiers which are based on substantial needs. This enables the vision to be long term action guiding and it increases the likelihood of realization and implementation.

\section{Need orientation in the two case studies}

Analysis of the two case studies showed that the need orientation has been the fundament and enabler for the successful formulation of a shared vision. Without the need orientation it would have been hardly possible to merge the ideas and visions of each participant to a common shared vision, because the ideas and visions of the participants were sometimes quite diverse. For example, in the OMV case study some participants' visions focused on implementing a consulting team into the internal audit department, while visions of other participants were directed on a further professionalization of the audit focus. The need orientation allowed participants to adopt the slogan "critical friend", which incorporates both diverse directions and enabled them to formulate the aspect of "dialogue partner" in the shared vision. In the SERI case study, a participant mentioned that "one of the greatest benefits of this vision development process was the consideration of the personal needs of all employees". Another participant argued that "this process made things conscious which have not been so clear and conscious for me before. This enabled us to put things into words in a very concrete way."

\subsection{A knowledge-based wavelike process: three steps and three discoveries}

The development of sustainable visions is characterized by a wavelike process of three steps and discoveries: (a) learning from an envisioned future and discovering attractive satisfiers and a "vision-1"; (b) crystallizing and deferring the basic essence and discovering the underlying substantial needs; (c) transforming, validating and applying those needs and preparing a sustainable vision.

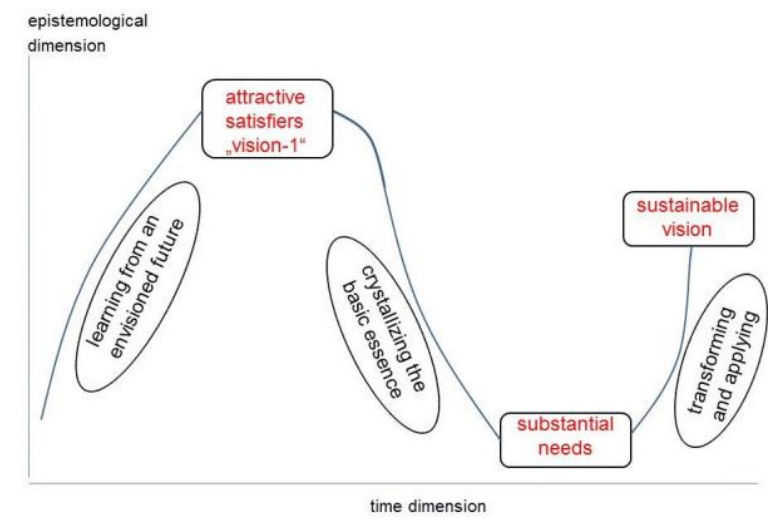

Figure 1: Wavelike process of three steps and their respective outputs

The $\mathrm{x}$-axis in our graphic of the wavelike process (figure-1) depicts the time dimension. According to Nonaka [11, p. 20] the y-axis can be described as epistemological dimension.

\subsubsection{Step-1}

The first step in this process covers learning from an envisioned future. It marks the upward movement within this wave. The discovery enabled by "learning from the future" are plenty of attractive satisfiers and based on those satisfiers, a "vision-1". This vision-1 can be seen as a first version of a vision, which is created spontaneously and inspired by the energy and enthusiasm of the participants, and therefore moves to the PEA [34] which is a characteristic of the "learning and interacting with an envisioned future"approach. However, this first version may on the one hand be incomplete and fragmentary and on the other hand it may contain some satisfiers which are not only visionary but even illusionary and there would not be a chance for realizing them at all.

Furthermore, vision-1 may not meet the requirements for a sustainable vision in the sense that realizing vision-1 could massively compromise the ability of others to meet their own needs [14]. It is important and valuable tough, to address satisfiers and (parts of) vision-1 even if they are not sustainable, because they can be used to infer the underlying needs and define alternative satisfiers based on the respective needs.

\section{Knowledge output of step-1}

Step-1 enables satisfier knowledge and selftranscending knowledge to emerge.

Explicit satisfier knowledge: This field of 
knowledge consists of explicit knowledge about dreams, wishes and ideas. They can be summarized as satisfiers which we articulate and externalize when answering the question "what do I really want?". Thereby, participants visualize concrete states and satisfiers. It is important to move persons and even whole social systems into the positive emotional attractor PEA [34] and therefore, to bundle energy to specify a picture of the vision. Satisfier knowledge is to some extend related to self-transcending knowledge. Self-transcending knowledge depicts a third kind of knowledge besides the established concepts of objective explicit knowledge and subjective tacit knowledge. It is defined as "tacit knowledge prior to its embodiment that describes the ability to sense and see the emerging opportunities before they become manifest in the marketplace" [35, p. 139]. Self-transcending knowledge is created when a person or a social system transcends the existing boundaries and evolves to "the next level" (of development). It is strongly connected with the "highest possible future self" and refers to "a territory of knowledge formation that is upstream from both explicit and tacit-embodied knowledge" [35, p. 139]. The generation of self-transcending knowledge is strongly enabled by the approach of learning from an envisioned future. The need orientation opens up a possibility spaces for new and innovative solutions and henceforward supports the emergence of selftranscending knowledge.

Explicit satisfier knowledge serves as an essential starting point for inferring explicit knowledge about needs [5].

\subsubsection{Step-2}

In the second step, the basic underlying essence of satisfiers and vision-1 is crystallized. The downward movement of this wave enables the emergence and discovery of substantial needs within the process of developing a sustainable vision. It is a form of an abductive reasoning process as described by Peirce [36] as well as a hermeneutical step [37]. From a knowledge-perspective, this step focuses on making explicit/visible the implicit part of vision-1 and its satisfiers. For step-2, approaches as generative knowledge interviewing [38] may be helpful.

\section{Knowledge output of step-2}

Step-2 enables explicit need knowledge about substantial needs to emerge.

Need knowledge can be created and externalized when answering the questions "what do I need for a fulfilling life and future?" as well as "why do I desire the imagined future?" Needs are the most fundamental basis in a hierarchy of needs, desires and their corresponding satisfiers. To satisfy a specific need, there are possible actions to be taken. Knowledge about needs is highly valuable because it enables us to find a variety of different solution strategies. Explicit need knowledge helps to escape binary decisions on actions (i.e. yes or no-decisions) and allows to develop alternative strategies.

\subsubsection{Step-3}

The third step outlines the transformation to and implementation of a sustainable vision based on the two discoveries and experiences during the process before. The implementation and transformation also considers the consequences for others when realizing this vision. This focuses on the common good and phronesis as mentioned above as well as on the requirements for a sustainable vision. In this phase, the actual requirements as well as possibilities of the system are considered. It transforms the essence (which was the result of phase-2) to the reality and enables to change the future reality of the system.

\section{Knowledge output of step-3}

Step-3 enables practical wisdom (phronesis) to emerge.

\section{Phronesis}

One important requirement of sustainable visions is that they not to only serve one's own substantial needs but also to bear in mind the common good. Only if those two are taken into account simultaneously, a vision has the potential to become a sustainable vision. Nonaka has introduced the concept of phronetic leadership [13]. He used the concept of phronesis (practical wisdom) which builds on Aristotele's distinction between three types of knowledge: episteme, techne and phronesis. Nonaka and Toyama describe phronesis as "high quality tacit knowledge acquired from practical experience that enables one to make prudent decisions and take action appropriate to each situation, guided by values and ethics." [11,p.377f]. In the context of vision development and referring to the Brundtland definition [14] of sustainability, phronesis means that sustainable visions address the substantial needs of an individual or a social system without compromising the ability of others and future generations to meet their own needs.

\subsubsection{The wave-like process at a glance}

It is important to point out again that the wavelike form of this process is one of the essential features of the proposed theory. The first upward movement enables creativity, phantasy, fun, joy, PEA, thinking out of the scope, transcending existing boundaries, detaching from restrictions and impossibilities, future-orientation, solution-orientation and hence a 
firework of exciting, innovative and fascinating ideas and satisfiers. However, it is highly likely that some parts of "vison-1", which is the output of this first upward movement, are not sustainable in the sense that they are either not possible to realize in any way or they compromise the ability of others to meet their own needs and desires. As Kim and Oki state, visioneering (i.e., the engineering of a clear vision) is different from visioning (i.e., imagining). Envisioning a sustainable world is an important first step toward sustainability. Without engineering, the vision will not stick as just visioning a sustainable future will remain as a daydream [6].

The downward movement enables the externalization of underlying substantial needs by grasping the essence, crystallizing main features, clustering similar and comparable ideas, abstracting and therefore preparing a fundament and space for innovative and sustainable solutions.

Finally, the second upward movement enables sustainability, commitment, action guiding, viability, innovation and finally articulating a sustainable vision. The first upward movement energizes and drives the downward movement and this pushes (moves) the second upward movement.

\section{The wave-like process in the two case studies}

The evaluation of the interviews of the SERI case study has shown that the wave-like process is sometimes challenging for the participants. The output of the upward movement is often very concrete and fascinating, yet after the downward movement, participants turn a little bit disappointed as the output is much more abstract and general. The second upward movement turns out to be more satisfying as its output is a concrete, attractive vision.

Analyzing the OMV case study reveals that the knowledge generated during the process was an important pillar of the vision. One participant mentioned: "One of the main positive learning I have picked up during this change process is that once people are offered the opportunity to contribute, they immediately get involved. Even if employees cannot affect the overall decision on the change process, their involvement in various stages of the process could bring new ideas and generate commitment. I think this was one of the biggest benefits of the process" [20]. Another participant mentioned as one of very positive experiences: "Group interactions and knowledge sharing among the hub”[20]

Evaluating the OMV case study clearly shows an interesting difference between the short vision, which can be seen as an output of step- 2 and the detailed vision (see section 2.5 of this paper), which is the result of the whole vision development process. While the first vision is rather abstract and reflects the common needs of the organization's members, the final vision is much more concrete and explicitly includes how to apply it in the everyday life of the organization. It now functions as guidance for each employee. It is the plan of OMV that deviant behavior should be addressed both in management meetings as well as appraisal interviews.

\section{Discussion, conclusion, further work}

The main outcome of this paper is the introduction of the theory wave as a knowledge-based theory for the development of sustainable visions. We have argued that the focus on sustainable visions as output seems to be very important and has a lot of interesting consequences for the vision development process.

\section{Knowledge-based aspects}

The process of developing sustainable visions is based on a strong knowledge orientation as well as knowledge creation. The ability to generate new knowledge and to transfer, use and apply existing knowledge is a crucial factor for systems in general and for companies in particular if they want to be capable to meet the future. One of the essential requirements for this process is the vision of the system. A holistic definition of knowledge has not been found yet, neither on individual nor on collective level. -A variety of epistemological and ontological assumptions lead to conceptual plurality and debate. We follow the definition of knowledge as capacity to act [39],[38,p.638] and a radical constructivist definition of knowledge in which knowledge is seen as something which the organism builds up in the attempt to order the as such amorphous flow of experience by establishing repeatable experiences and relatively reliable relations between them [41, p. 24]. So knowledge orientation in the context of vision development touches two main aspects:

First, the vision development process is a knowledge creating process by itself. It generates knowledge to act in the here and now to achieve the ideal future described in the vision.

Second, knowledge orientation means gaining knowledge and using this knowledge to build up and specify a vision. It constitutes and enhances the capacity to act based on this vision. So vision development can be seen as a knowledge creating and knowledge transforming process. It evolves around four different fields of knowledge: explicit need knowledge, explicit satisfier knowledge, phronesis and implicit need knowledge. We introduced the first three types of knowledge in 
section 3.3 of this paper. Now we suggest a definition for implicit need knowledge.

\section{Implicit need knowledge}

McLeod emphasizes that "needs are not themselves experienced" [28, p.215]. They are not to be confused with the desires they generate. So knowledge about needs cannot be accessed directly [30]. However, implicit need knowledge is an already existing and important as well as invisible fundament and part of the decisions we make in our life. Furthermore, it is an implicit but very important enabler for the emergence of explicit satisfier knowledge.

We briefly outlined four fields of knowledge which have an intense connection to purpose and calling as they are strongly interrelated. Their interaction and conversion drives the process of vision development in a similar way as the SECI knowledge spiral drives the creation of new knowledge [42].

- Implicit need knowledge is necessary to generate explicit satisfier knowledge (step-1 theory wave).

- Explicit satisfier knowledge can be transformed into explicit need knowledge by applying generative listening and abductive reasoning (step-2 of theory wave).

- Finally, explicit need knowledge together with phronesis enables the creation of sustainable visions (step-3 of theory wave).

As the development of our theory builds on theoretical engagement with literature and insights of the two case studies described in this paper, it seems to be plausible that the theory wave can serve as a solid and consistent theoretical fundament for the development of sustainable visions. Moreover, it might be possible to apply this theory to different levels of human organization, since the main aspects of the theory can be found in both case studies although the two case studies have very different scopes. According to the structure of theory wave its area of consideration covers entrepreneurial visions as well as visions for social systems and personal visions. While the capacity to meet human needs is relevant for all areas, especially the long term view on organizations' sustainability has to be focused on step-3 in the case of entrepreneurial visions.

\section{Limitations and future research}

However, theory wave has to be tested in the future with data from vision development processes that have completely different scopes than of the one's of our two case studies. The case of OMV represents a department within a large company, the case of SERI represents a small company. Of course there are numerous other levels of organizations; therefore it seems to be necessary for further work to analyze some studies in the field of management and research across (organizational) levels (e.g. [43], [44]). Further work will cover the following areas:

- Testing the theory wave in additional case studies with different scopes

- Deriving (maybe different) concrete methods based on the theory wave for vision development processes in systems with various requirements and structures

\section{References}

[1] I. Nonaka, R. Toyama, and T. Hirata, Managing Flow: A Process Theory of the Knowledge-Based Firm, Basingstoke/New York: Palgrave Macmillan, 2008.

[2] D. O'Connell, K. Hickerson, and a. Pillutla, "Organizational Visioning: An Integrative Review," Gr. Organ. Manag., vol. 36, pp. 103-125, 2011.

[3] A. D. Masuda, et al., "The role of a vivid and challenging personal vision in goal hierarchies.," $J$. Psychol., vol. 144, no. 3, pp. 221-242, 2010.

[4] S. J. Zaccaro and D. Banks, "Leadership, vision, and organizational effectiveness," in The nature of organizational leadership: understanding the performance imperatives confronting today's leaders, 2001, pp. 181-218.

[5] A. Kaiser, B. Feldhusen, and B. Fordinal, "Vision Development as a Knowledge Creating Process," in Proceedings of the HICSS-46 conference, 2013, pp. 3593-3602.

[6] J. Kim and T. Oki, "Visioneering: An essential framework in sustainability science," Sustain. Sci., vol. 6, pp. 247-251, 2011.

[7] J. Collins and J. Porras, "Building Your Company's Vision," Harv. Bus. Rev., vol. 74, no. 5, pp. 65-77, 1996.

[8] P. M. Senge, "The Leader's New Work: Building Learning Organizations," Sloan Managment. Review., vol. 32, no. 1, pp. 7-23, 1990.

[9] R. E. Boyatzis, "An overview of intentional change from a complexity perspective," J. Manag. Dev., vol. 25, no. 7, pp. 607-623, Aug. 2006.

[10] R. E. Boyatzis and K. Akrivou, "The ideal self as the driver of intentional change," J. Manag. Dev., vol. 25, no. 7, pp. 624-642, Aug. 2006.

[11] I. Nonaka, "A Dynamic Theory of Organizational Knowledge Creation," Organization Science, vol. 5, no. 1. pp. 14-37, Feb-1994.

[12] I. Nonaka and R. Toyama, "The theory of the knowledge-creating firm: subjectivity, objectivity and synthesis," Ind. Corp. Chang., vol. 14, no. 3, pp. 419-436, 2005.

[13] I. Nonaka and R. Toyama, "Strategic management as distributed practical wisdom 
(phronesis)," Ind. Corp. Chang., vol. 16, no. 3, pp. 371-394, May 2007.

[14] United Nations World Commission on Environment and Development, "Our Common Future," 1987.

[15] R. Van der Helm, "The vision phenomenon: Towards a theoretical underpinning of visions of the future and the process of envisioning," Futures, vol. 41, no. 2, pp. 96-104, Mar. 2009.

[16] N. Papalexandris and E. Galanaki, "Leadership's impact on employee engagement," Leadersh. Organ. Dev. J., vol. 30, no. 4, pp. 365385, 2009.

[17] K. M. Eisenhardt, "Building theories from case study research," Acad. Manag. Rev., vol. 14, no. 4, pp. 532-550, 1989.

[18] R. Yin, Case Study Research Design and Methods. Beverly Hills: Sage Publications, 1994.

[19] K. M. Eisenhardt and M. E. Graebner,"Theory building from cases: Opportunities and challenges". Academy of Management Journal, 50(1),pp.25-32, 2007.

[20] E. Petri, "Strategische Neuausrichtung einer hoch entwickelten Stabsabteilung im Rahmen eines kombinierten Bottom up/Top down Prozesses am Beispiel der „Corporate Internal Audit“ Funktion der OMV Aktiengesellschaft,” Univ. St.Gallen, 2015.

[21] B. Fordinal, "Berufungscoaching im Visionsentwicklungsprozess Eine Untersuchung der Methode im Kontext einer sinn- und werteorientierten Personal- und Organisationsentwicklung," Donau Universität Krems, 2007.

[22] D. T. Gilbert and T. D. Wilson, "Prospection: experiencing the future.," Science, vol. 317, no. 5843, pp. 1351-4, 2007.

[23] C. O. Scharmer and K. Kaeufer, Leading from the emerging future: from ego-system to eco-system economies. San Francisco, CA: Berret-Koehler Publishers, 2013.

[24] C. O. Scharmer, Theory U. Leading from the future as it emerges. San Francisco, CA: BerretKoehler Publishers, 2009.

[25] D. A. Kolb, Experiential learning: experience as the source of learning and development. Englewood Cliffs, NJ: Prentice Hall, 1984.

[26] K. K. Szpunar, J. M. Watson, and K. B. McDermott, "Neural substrates of envisioning the future.," Proc. Natl. Acad. Sci. U.S.A., vol. 104, no. 2, pp. 642-647, 2007.

[27] G. Bateson, Steps to an ecology of mind: Collected essays in anthropology, psychiatry, evolution, and epistemology. 1972.

[28] F. Kragulj, "Interacting with the Envisioned Future as a Constructivist Approach to Learning," Constr. Found., vol. 9, no. 3, pp. 439-440, 2014.
[29] K. K. Szpunar, "Episodic Future Thought: An Emerging Concept," Psychol. Sci., vol. 5, pp. 142162, 2010.

[30] S. McLeod, "Knowledge of Need," Int. J. Philos. Stud., vol. 19, no. 2, pp. 211-230, Jun. 2011.

[31] M. Max-Neef, "Development and human needs," in Ekins, P. and Max-Neef, M., editors, RealLife Economics: Understanding Wealth Creation, 1992, pp. 197-213.

[32] D. Wiggins and S. Dermen, "Needs, need, needing.," J. Med. Ethics, vol. 13, no. 2, pp. 62-68, Jun. 1987.

[33] G. Thomson, "Fundamental Needs," in Royal Institute of Philosophy Supplement, vol. 57, S. Reader, Ed. Cambridge: Royal Institute of Philosophy Supplement, 2005, pp. 175-186.

[34] R. Boyatzis, "Coaching with compassion: Inspiring health, well-being, and development in organizations," J. Appl. Behav. Sci., vol. 49, no. 2, pp. 153-178, Nov. 2012.

[35] O. Scharmer, "Self-transcending knowledge: sensing and organizing around emerging opportunities," J. Knowl. Manag., vol. 5, no. 2, pp. 137-151, 2001.

[36] C. S. Peirce, Collected Papers of Charles Sanders Peirce. Harvard University Press, 1958.

[37] H. G. Gadamer, Truth and method. Continuum, 2004.

[38] M. Peet, K. Walsh, R. Sober, and C. Rawak, "Generative Knowledge Interviewing: A method for knowledge transfer and talent management at the University of Michigan," Int. J. Educ. Adv., vol. 10, no. 2, pp. 71-85, Sep. 2010.

[39] K.-E. Sveiby, The New Organizational Wealth: Managing and Measuring Knowledge-Based Assets. San Francisco: Berrett-Koehler Publishers, 1997.

[40] G. Von Krogh and I. Nonaka, "Tacit Knowledge and Knowledge Conversion: Controversy and Advancement in Organizational," Organ. Sci., vol. 20, no. 3, pp. 635-652, Jan. 2009.

[41] E. Glasersfeld, "An Introduction to Radical Constructivism," in The Invented Reality, P. Watzlawick, Ed. New York: Norton, 1984.

[42] I. Nonaka, R. Toyama, and A. Nagata, "A Firm as a Knowledge-creating Entity: A New Perspective on the Theory of the Firm," Ind. Corp. Chang., vol. 9, no. 1, pp. 1-20, 2000.

[43] A. Hwang, N. Khatri, and E. S. Srinivas, "Organizational charisma and vision across three countries," Manag. Decis., vol. 43, no. 7/8, pp. 960974, 2005.

[44] M. A. Hitt et al., "Building theoretical and empirical bridges across levels: Multilevel research in management," Acad. Manag. J., vol. 50, no. 6, pp. 1385-1399, 2007. 